\title{
Kinetics of low-temperature catalytic combustion of ethylene at wet conditions for postharvest storage applications
}

\author{
Natalia Semagina ${ }^{1}$, Rosanne Tam $^{1}$, and James Sawada ${ }^{2}$ \\ ${ }^{1}$ University of Alberta Faculty of Engineering \\ ${ }^{2}$ Climacteric Controls Solutions, Inc
}

December 30, 2021

\begin{abstract}
The study addresses the reduction of ethylene levels in postharvest storage applications using a Pd-Zn-Sn/TiO2 catalyst, which is capable of reacting trace concentrations of ethylene at temperatures as low as $278 \mathrm{~K}$ and at relative humidity as high as $90 \%$. The rate law is derived from data collected using a constant volume batch reactor and a model for a storage room with associated packed bed reactor is developed. The amount of catalyst required to maintain an ethylene concentration of $0.1 \mathrm{ppmv}$ in a room containing 20 tons of fruit having an ethylene metabolism of $0.1 \mathrm{ul} / \mathrm{kg} \mathrm{hr}$ was calculated as a function of air temperature and water content. While the catalyst is capable of continuously removing ethylene from saturated, refrigerated air, the amount of catalyst required can be reduced significantly by incorporating conventional air conditioning solutions upstream of the catalyst bed. Such combined systems and their functions are discussed
\end{abstract}

\section{Hosted file}

Final.pdf available at https://authorea.com/users/453163/articles/551077-kinetics-of-lowtemperature-catalytic-combustion-of-ethylene-at-wet-conditions-for-postharvest-storageapplications 